Journal of Systems Science and Information

Oct., 2016, Vol. 4, No. 5, pp. 428-443

DOI: $10.21078 /$ JSSI-2016-428-16

\title{
Multi-Period Mean-Absolute Deviation Fuzzy Portfolio Selection Model with Entropy Constraints
}

\author{
Peng ZHANG \\ School of Economics, Wuhan University of Technology, Wuhan 430070, China \\ E-mail: zhangpeng300478@aliyun.com \\ Heshan GONG \\ School of Economics, Wuhan University of Technology, Wuhan 430070, China \\ Weiting LAN \\ School of Economics, Wuhan University of Technology, Wuhan 430070, China
}

\begin{abstract}
This paper considers a multi-period fuzzy portfolio selection problem maximizing the terminal wealth imposed by risk control, in which the returns of assets are characterized by fuzzy numbers. A fuzzy absolute deviation is originally defined as the risk control of portfolio. Entropy constraints and borrowing constraints are added in the portfolio selection model. Based on the theories of possibility measures, a new multi-period portfolio optimization model with transaction costs is proposed. And then, the proposed model is transformed into a crisp nonlinear programming problem by using fuzzy programming approach. Because of the transaction costs, the multi-period portfolio selection is the dynamic optimization problem with path dependence. Through changing the cost function into a variable, the multi-period portfolio selection is approximately turned into the dynamic programming. Furthermore, the discrete approximate iteration method is designed to obtain the optimal portfolio strategy. Finally, an example is given to illustrate the behavior of the proposed model and the designed algorithm using real data from the Shanghai Stock Exchange.
\end{abstract}

Keywords multi-period fuzzy portfolio selection; mean absolute deviation; transaction costs; entropy constraints; discrete approximate iteration method

\section{Introduction}

In 1952, Markowitz ${ }^{[1]}$ published his pioneering work which laid the foundation of modern portfolio analysis. Markowitzs model has served as a basis for the development of modern financial theory over the past six decades. However, contrary to its theoretical reputation, it is not used extensively to construct large-scale portfolios. One of the most important reasons for this is the computational difficulty associated with solving a large-scale quadratic programming problem with a dense covariance matrix. Konno and Yamazaki ${ }^{[2]}$ used the absolute deviation risk function to replace the risk function in Markowitzs model and formulated a mean absolute deviation portfolio optimization model. It turns out that the mean absolute deviation model

Received March 14, 2014, accepted May 21, 2014

Supported by the National Natural Science Foundation of China $(71271161,71301144)$ 
maintains the favorable properties of Markowitz's model and removes most of the principal difficulties in solving Markowitz's model. Simaan ${ }^{[3]}$ provided a thorough comparison of the mean variance model and the mean absolute deviation model. Furthermore, Speranza ${ }^{[4]}$ used the semi-absolute deviation to measure the risk and formulated a portfolio selection model. Feinstein and Thapa ${ }^{[5]}$ proposed the average absolute deviation to measure risk.

For those models above, they are assumed that the investment horizon is single-period. But, in real world, the portfolio strategies are usually multi-period, since the investor can reallocate his wealth from time to time. So, it is natural to extend the single-period portfolio selections to multi-period portfolio selections. Mossin ${ }^{[6]}$ presented optimal multiperiod portfolio selection policies by using dynamic programming approach. Hakansson ${ }^{[7]}$ analyzed the multi-period mean-variance by means of a general theory of portfolio choice. Li, Chan, and $\mathrm{Ng}^{[8]}$ employed dynamic programming approach to deal with the multi-period safety-first portfolio selection problem. Using the same approach, $\mathrm{Li}$ and $\mathrm{Ng}^{[9]}$ considered the mean-variance formulation for the multi-period portfolio selection problem and determined the optimal portfolio selection policy and an analytical expression of the mean-variance efficient frontier. Calafiore ${ }^{[10]}$ concerned with multi-period sequential decision problems for financial asset allocation and presented a multi-period optimization with linear control policies. Zhu, et al. ${ }^{[11]}$ proposed a dynamic meanvariance portfolio selection model with risk control over bankruptcy. Wei and $\mathrm{Ye}^{[12]}$ proposed a multi-period mean-variance portfolio selection model with bankruptcy control in stochastic market. Güpınar and Rustem ${ }^{[13]}$ constructed a multi-period mean-variance optimization framework for the stochastic aspects of the scenario tree. Yu, et al. ${ }^{[14]}$ proposed a dynamic portfolio selection optimization with bankruptcy control for absolute deviation model. Çlikyurt and Özekici ${ }^{[15]}$ introduced several multi-period portfolio optimization models in stochastic markets using the mean-variance approach. However, all the literatures mentioned above, they often used variance as a risk measure. Since in case when return distributions of assets are asymmetric, using the variance as the risk measure may have a potential danger to sacrifice too much expected return in eliminating both low and high return extremes. To express or measure the real investment risk in financial market, scholars have employed some new risk measures to replace variance. Such as, Yan and $\mathrm{Li}^{[16]}$ and Yan, et al. ${ }^{[17]}$ substituted variance with semivariance as the risk measure to deal with the multi-period portfolio selection problem. Pinar ${ }^{[18]}$ used the downside-risk measure as risk measure to study the multi-period portfolio selection problem. Considering the linear transaction costs, diversification degree of portfolio and skewness, Zhang, et al. ${ }^{[19,20]}$ and Liu, et al. ${ }^{[21,22]}$ proposed multiperiod fuzzy portfolio selection, and genetic algorithm, hybrid intelligent algorithm and differential evolution algorithm were proposed to solve them.

There are many non-probabilistic factors that affect the financial markets such that the return of risky asset is fuzzy uncertainty. Recently, a number of researchers investigated fuzzy portfolio selection problem. Watada ${ }^{[23]}$ and León, et al. ${ }^{[24]}$ discussed portfolio selection using fuzzy decision theory. Tanaka and Guo ${ }^{[25,26]}$ proposed two kinds of portfolio selection models based on fuzzy probabilities and exponential possibility distributions, respectively. Inuiguchi and Tanino ${ }^{[27]}$ introduced a possibilistic programming approach to the portfolio selection problem based on the minimax regret criterion. Wang and $\mathrm{Zhu}^{[28]}$, Lai, et al. ${ }^{[29]}$ and Giove, et 
al. ${ }^{[30]}$ constructed interval programming models of portfolio selection. Zhang and $\mathrm{Nie}^{[31]}$ and Zhang, et al. ${ }^{[32]}$ discussed the admissible efficient portfolio selection under the assumption that the expected return and risk of asset have admissible errors to reflect the uncertainty in real investment actions and gave an analytic derivation of admissible efficient frontier when short sales are not allowed on all risky assets. Dubois and Prade ${ }^{[33]}$ defined an interval-valued expectation of fuzzy numbers, viewing them as consonant random sets. They also showed that this expectation remains additive in the sense of addition of fuzzy numbers. Carlsson and Fullér ${ }^{[34]}$ introduced the notions of lower and upper possibilistic mean values of a fuzzy number, viewing them as possibility distributions. Huang ${ }^{[35-37]}$ proposed mean variance, mean semi-variance and mean risk curve portfolio selection models. Zhang, et al. ${ }^{[38]}$, Zhang ${ }^{[39]}$, Zhang and Xiao ${ }^{[40]}$ proposed the portfolio selection models based on the lower and upper possibilistic means and possibilistic variances of fuzzy numbers. Li, et al. ${ }^{[41,42]}$ proposed mean- variance and meanvariance-skewness fuzzy portfolio, and used hybrid intelligent algorithms to solve them. Carlsson, et al. ${ }^{[43]}$ introduced a possibilistic approach to selecting portfolios with highest utility score under the assumption that the returns of assets are trapezoidal fuzzy numbers.

In this study, we propose the dynamic optimization model for multi-period portfolio rebalancing with cardinality constraints that is mix integer nonlinear. This paper is organized as follows. In Section 2, we introduce the definitions of the possibilistic mean, the possibilistic absolute deviation, and some properties. In Section 3, we formulate the possibilistic return, the possibilistic absolute deviation, cardinality constraints, borrowing constraints and transaction costs into the multi-period portfolio. We construct a multi-period portfolio selection model in Section 4, then through changing the cost function into a variable, the model is converted into a dynamic programming model, the discrete approximate iteration method is proposed to solve it, and the method is proved convergent. In Section 5, we give the comparison analysis of different entropies to illustrate the idea of our model and the effectiveness of the designed algorithm. Finally, some conclusions are given in Section 6 .

\section{Preliminaries}

Let us introduce some definitions, which we need in the following section. A fuzzy number $A$ is a fuzzy set of the real line $R$ with a normal, fuzzy convex and continuous membership function of bounded support. The family of fuzzy numbers is denoted by $F$.

Carlsson and Fullér ${ }^{[34]}$ defined the lower and upper possibilistic mean values of fuzzy number $A$ with $\gamma$-level set $[A]^{\gamma}=\left[a_{1}(\gamma), a_{2}(\gamma)\right](\gamma \in[0,1])$ as

$$
M_{*}(A)=\frac{\int_{0}^{1} a_{1}(\gamma) \operatorname{Pos}\left(A \leq a_{1}(\gamma)\right) \mathrm{d} \gamma}{\int_{0}^{1} \operatorname{Pos}\left(A \leq a_{1}(\gamma)\right) \mathrm{d} \gamma}=2 \int_{0}^{1} \gamma a_{1}(\gamma) \mathrm{d} \gamma
$$

and

$$
M^{*}(A)=\frac{\int_{0}^{1} a_{2}(\gamma) \operatorname{Pos}\left(A \geq a_{2}(\gamma)\right) \mathrm{d} \gamma}{\int_{0}^{1} \operatorname{Pos}\left(A \geq a_{2}(\gamma)\right) \mathrm{d} \gamma}=2 \int_{0}^{1} \gamma a_{2}(\gamma) \mathrm{d} \gamma
$$

where Pos denotes possibility, i.e.,

$$
\operatorname{Pos}\left(A \leq a_{1}(\gamma)\right)=\prod\left(-\infty, a_{1}(\gamma)\right)=\sup _{u \leq a_{1}(\gamma)} A(u)=\gamma
$$




$$
\operatorname{Pos}\left(A \geq a_{2}(\gamma)\right)=\prod\left(a_{2}(\gamma),+\infty\right)=\sup _{u \geq a_{2}(\gamma)} A(u)=\gamma
$$

Let $A, B \in F$, and let $\lambda \in R$, Then the following results can be found in [50].

$$
\begin{gathered}
M_{*}(A+B)=M_{*}(A)+M_{*}(B), M^{*}(A+B)=M^{*}(A)+M^{*}(B), \\
M_{*}(\lambda A)= \begin{cases}\lambda M_{*}(A), & \text { if } \lambda \geq 0, \\
\lambda M^{*}(A), & \text { if } \lambda<0,\end{cases}
\end{gathered}
$$

and

$$
M^{*}(\lambda A)= \begin{cases}\lambda M^{*}(A), & \text { if } \lambda \geq 0, \\ \lambda M_{*}(A), & \text { if } \lambda<0 .\end{cases}
$$

According to above results, it's easy to get the following theorem.

Theorem 1 Let $A_{i} \in F$ and let $\lambda_{i} \in R_{i}, i=1,2, \cdots, n$. Then

$$
\begin{aligned}
& M_{*}\left(\sum_{i=1}^{n} \lambda_{i} A_{i}\right)=\sum_{i=1}^{n}\left|\lambda_{i}\right| M_{*}\left(\phi\left(\lambda_{i}\right) A_{i}\right), \\
& M^{*}\left(\sum_{i=1}^{n} \lambda_{i} A_{i}\right)=\sum_{i=1}^{n}\left|\lambda_{i}\right| M^{*}\left(\phi\left(\lambda_{i}\right) A_{i}\right),
\end{aligned}
$$

where $\phi\left(\lambda_{i}\right)$ is a sign function.

Definition 1 (Carlsson and Fullér ${ }^{[34]}$ ) Let $A$ be a fuzzy number with $[A]^{\gamma}=\left[a_{1}(\gamma), a_{2}(\gamma)\right]$ $(\gamma \in[0,1])$. Then the crisp possibilistic mean is defined as

$$
\bar{M}(A)=\left(M^{*}(A)+M_{*}(A)\right) / 2=\int_{0}^{1} \gamma\left(a_{1}(\gamma)+a_{2}(\gamma)\right) \mathrm{d} \gamma .
$$

Definition 2 For any two given fuzzy numbers $A$ with $[A]^{\gamma}=\left[a_{1}(\gamma), a_{2}(\gamma)\right](\gamma \in[0,1])$ and $B$ with $[B]^{\gamma}=\left[b_{1}(\gamma), b_{2}(\gamma)\right](\gamma \in[0,1])$, the possibilistic absolute deviation between $A$ and $B$ is defined as

$$
\omega(A, B)=\frac{1}{2}(\bar{M}|A+B-\bar{M}(A)-\bar{M}(B)|) .
$$

A popular fuzzy number is trapezoidal fuzzy number $A=\left(a_{l}, b_{l}, \alpha_{l}, \beta_{l}\right)$ with membership function $\mu_{A}(x)$ in the following form

$$
\mu_{A}(x)= \begin{cases}\frac{x-\left(a_{l}-\alpha_{l}\right)}{\alpha_{l}}, & x \in\left[a_{l}-\alpha_{l}, a_{l}\right], \\ 1, & x \in\left[a_{l}, b_{l}\right], \\ \frac{b_{l}+\beta_{l}-x}{\beta_{l}}, & x \in\left[b_{l}, b_{l}+\beta_{l}\right], \\ 0, & \text { otherwise, }\end{cases}
$$

where $\alpha_{l}$ and $\beta_{l}$ are positive numbers, i.e., $\alpha_{l}, \beta_{l}>0$. Thus, the $\gamma$-level set of trapezoidal fuzzy number $A=\left(a_{l}, b_{l}, \alpha_{l}, \beta_{l}\right)$ can be expressed as $\left[A_{l}\right]^{\gamma}=\left[a_{l}-(1-\gamma) \alpha_{l}, b_{l}+(1-\gamma) \beta_{l}\right]$, for all $\gamma \in[0,1]$. 
By Definition 1, the lower and upper possibilistic means and the possibilistic mean value are respectively expressed as

$$
\begin{aligned}
& M_{*}\left(A_{i}\right)=a_{i}-\alpha_{i} / 3, \\
& M^{*}\left(A_{i}\right)=b_{i}+\beta_{i} / 3, \\
& \bar{M}\left(A_{i}\right)=\frac{a_{i}+b_{i}}{2}+\frac{\beta_{i}-\alpha_{i}}{6} .
\end{aligned}
$$

\section{The Formulation of Multi-Period Portfolio Selection Problem}

In this section, we discuss the multi-period portfolio selection problem with fuzzy returns. We first introduce the problem description and notations used in the following section. Then, we formulate the possibilistic return and risk of multi-period portfolio. Finally, we present cardinality constraints.

\subsection{Problem Description and Notations}

Let us consider a multi-period portfolio selection problem with $n$ risky assets and a risk-free asset. The return rates of risky assets are denoted as fuzzy variables. Assume that an investor joins the market at the beginning of period 1 with initial wealth $W_{1}$. The investor intends to allocate his/her wealth among the $n+1$ assets for making $T$ periods investment plan. His/her wealth can be reallocated among the $n+1$ assets at the beginning of the following $T$ consecutive time periods. To make it easier to follow our exposition, we put together all the notations that will be used hereafter.

$x_{i t}$ the investment proportion of risky asset $i$ at period $t$;

$x_{i 0}$ the initial investment proportion of risky asset $i$ at period 1 ;

$x_{t}$ the portfolio at period $t$, where $x_{t}=\left(x_{1 t}, x_{2 t}, \cdots, x_{n t}\right)$;

$x_{f t}$ the investment proportion of risk-free asset at period $t$, where $x_{f t}=1-\sum_{i=1}^{n} x_{i t}$;

$x_{f t}^{b}$ the lower bound of the investment proportion of risk-free asset at period $t$, where $x_{f t} \geq x_{f t}^{b} ;$

$R_{i t}$ the return of risky asset $i$ at period $t$;

$r_{p t}$ the return rate of the portfolio $x_{t}$ at period $t$;

$r_{b t}$ the borrowing rate of the risk-free asset at period $t$;

$r_{l t}$ the lending rate of the risk-free asset at period $t$;

$u_{i t}$ the upper bound constraints of $x_{i t}$;

$r_{N t}$ the net return rate of the portfolio $x_{t}$ at period $t$;

$W_{t}$ the crisp form of the holding wealth at the beginning of period $t$;

$c_{i t}$ the unit transaction cost of risky asset $i$ at period $t$;

$K$ the desired number of assets in the portfolio at period $t$.

\subsection{Possibilistic Return and Risk for Multi-Period Portfolio}

As we know, in practical investment, different investors with different preferences may result from investment strategies. In order to achieve greater flexibility in portfolio selection, it is necessary to consider multiple criteria for expressing investors preferences. In the following subsections, we will introduce the criteria, including return, transaction cost, risk and the cardinality constraints of portfolio. We will quantify return by the possibilistic mean value and 
risk by possibilistic absolute deviation about the fuzzy return of the asset. Assume that the whole investment process is self- financing, that is, the investor does not invest the additional capital during the portfolio selection. The return of risky asset, $R_{i t}=\left(a_{i t}, b_{i t}, \alpha_{i t}, \beta_{i t}\right)(i=$ $1,2, \cdots, n ; t=1,2, \cdots, T)$ are trapezoidal fuzzy numbers.

The borrowing constraints of portfolio selection are one of factors. Most of the brokerage houses provide the opportunity to make an acquisition on different assets by borrowing the money from the brokerage. Some researchers studied the borrowing constraints, for example, Deng and $\mathrm{Li}^{[44]}$ proposed a mean-variance fuzzy portfolio with borrowing constraint. Sadjadi, et al. ${ }^{[45]}$ proposed the fuzzy multi-period portfolio model with different rates for borrowing and lending. The borrowing constraints are taken account into the model. Then, derived from Equation (3), the possibilistic mean value of the portfolio $x_{t}=\left(x_{1 t}, x_{2 t}, \cdots, x_{n t}\right)^{\prime}$ at period $t$ can be expressed as

$$
\begin{aligned}
r_{p t} & =\sum_{i=1}^{n} \bar{M}\left(R_{i t}\right) x_{i t}+r_{f t}\left(1-\sum_{i=1}^{n} x_{i t}\right) \\
& =\sum_{i=1}^{n}\left(\frac{a_{i t}+b_{i t}}{2}+\frac{\beta_{i t}-\alpha_{i t}}{6}\right) x_{i t}+r_{f t}\left(1-\sum_{i=1}^{n} x_{i t}\right), \quad t=1,2, \cdots, T,
\end{aligned}
$$

where

$$
r_{f t}=\left\{\begin{array}{l}
r_{l t}, \quad 1-\sum_{i=1}^{n} x_{i t} \geq 0, \\
r_{b t}, \quad 1-\sum_{i=1}^{n} x_{i t} \leq 0,
\end{array} \quad r_{b t} \geq r_{l t} .\right.
$$

Transaction cost is one of the main concerns for portfolio managers. Arnott and Wagner ${ }^{[46]}$ found that ignoring transaction costs would result in an inefficient portfolio. Yoshimoto's empirical analysis ${ }^{[47]}$ also drew the same conclusion. Bertsimas and Pachamanova ${ }^{[48]}$ and Gulpinar, et al. ${ }^{[49]}$ incorporated transaction costs into consideration to study the multi-period portfolio selection problem. We also assume that the transaction cost is a V-shaped function of differences between the $t$ th period portfolio $x_{t}=\left(x_{1 t}, x_{2 t}, \cdots, x_{n t}\right)$ and the $(t-1)$ th period portfolio $x_{t-1}=\left(x_{1 t-1}, x_{2 t-1}, \cdots, x_{n t-1}\right)$. That's to say, the transaction cost for asset $i$ at period $t$ is $c_{i t}\left|x_{i t}-x_{i t-1}\right|$. Hence, the total transaction cost of the portfolio $x_{t}=\left(x_{1 t}, x_{2 t}, \cdots, x_{n t}\right)$ at period $t$ can be expressed as

$$
C_{t}=\sum_{i=1}^{n} c_{i t}\left|x_{i t}-x_{i t-1}\right|, \quad t=1,2, \cdots, T .
$$

Thus, the net return rate of the portfolio $x_{t}$ at period $t$ can be denoted as

$$
\begin{aligned}
r_{N t}= & \sum_{i=1}^{n}\left(\frac{a_{i t}+b_{i t}}{2}+\frac{\beta_{i t}-\alpha_{i t}}{6}\right) x_{i t}+r_{f t}\left(1-\sum_{i=1}^{n} x_{i t}\right) \\
& -\sum_{i=1}^{n} c_{i t}\left|x_{i t}-x_{i t-1}\right|, \quad t=1,2, \cdots, T .
\end{aligned}
$$

Then, the crisp form of the holding wealth at the beginning of the period $t$ can be written as

$$
W_{t+1}=W_{t}\left(1+r_{N t}\right)
$$




$$
\begin{aligned}
=W_{t}( & 1+\sum_{i=1}^{n}\left(\frac{a_{i t}+b_{i t}}{2}+\frac{\beta_{i t}-\alpha_{i t}}{6}\right) x_{i t}+r_{f t}\left(1-\sum_{i=1}^{n} x_{i t}\right) \\
& \left.-\sum_{i=1}^{n} c_{i t}\left|x_{i t}-x_{i t-1}\right|\right), \quad t=1,2, \cdots, T .
\end{aligned}
$$

Derived from Equation (2), the possibilistic absolute deviation of the portfolio $x_{t}$ can be expressed as

$$
v_{t}=\bar{M}\left(\left|\sum_{i=1}^{n}\left(\bar{M}\left(R_{i t}\right)-R_{i t}\right) x_{i t}\right|\right) .
$$

Theorem 2 Let $R_{i t}=\left(a_{i t}, b_{i t}, \alpha_{i t}, \beta_{i t}\right)$ be trapezoidal fuzzy numbers, $x_{i t} \geq 0(i=$ $1,2, \cdots, n ; t=1,2, \cdots, T)$. Then

$$
v_{t}=\sum_{i=1}^{n}\left(b_{i t}-a_{i t}+\frac{\beta_{i t}+\alpha_{i t}}{3}\right) x_{i t} .
$$

Proof Suppose $x_{i t} \geq 0$, then

$$
v_{t}=\bar{M}\left(\left|\sum_{i=1}^{n}\left(\bar{M}\left(R_{i t}\right)-R_{i t}\right) x_{i t}\right|\right)=\sum_{i=1}^{n} \bar{M}\left|\left(\bar{M}\left(R_{i t}\right)-R_{i t}\right)\right| x_{i t} .
$$

According to the define of the absolute deviation of the portfolio $x_{t}$, then

$$
v_{t}=\sum_{i=1}^{n} \bar{M}\left(\max \left\{0, \bar{M}\left(R_{i t}\right)-R_{i t}\right\}-\min \left\{0, \bar{M}\left(R_{i t}\right)-R_{i t}\right\}\right) .
$$

Suppose $R_{i t}=\left(a_{i t}, b_{i t}, \alpha_{i t}, \beta_{i t}\right)$ be trapezoidal fuzzy numbers, then Equation (10) can be turned into

$$
v_{t}=\sum_{i=1}^{n} \bar{M}\left(\left[0, b_{i t}-a_{i t}+\frac{\beta_{i t}}{3}, 0, \alpha_{i t}\right]+\left[b_{i t}-a_{i t}+\frac{\alpha_{i t}}{3}, 0, \beta_{i t}, 0\right]\right) .
$$

Derived from Equation (3), then Equation (11) can be turned into $v_{t}=\sum_{i=1}^{n}\left(b_{i t}-a_{i t}+\right.$ $\left.\frac{\beta_{i t}+\alpha_{i t}}{3}\right) x_{i t}$, Which ends the proof.

In order to satisfy the requisition of decentralized investment, a novel possibilistic entropy will be developed to measure the diversification degree of portfolio. Before introducing the possibilistic entropy, let us first review the existing proportion entropy, which is employed to reflect the diversification degree of single-period portfolio selection problem in Fang, et al. ${ }^{[50]}$, Kapur ${ }^{[51]}$ and Jana, et al. ${ }^{[52]}$. And the possibilistic entropy of the portfolio $x_{t}$ can be expressed as follows:

$$
\operatorname{En}\left(x_{t}\right)=-\sum_{i=1}^{n} x_{i t} \ln x_{i t} .
$$

From Equation (12), we have $x_{i t} \geq 0(i=1,2, \cdots, n)$, that is, every asset must be chosen for constructing a portfolio. Note that when $x_{1 t}=x_{2 t}=\cdots=1 / n$, Equation (12) takes its maximum value. In other words, the diversification degree of the portfolio is the maximum. However, in the practical investment management, an investor often may not hope to distribute his/her wealth among every asset for constructing an extremely diversified portfolio. In particular, when the investor forecasts the rate of return on asset $i, R_{i t}$, is less than the risk-free return rate, the investor may not support investment in asset $i$, namely, $x_{i t}=0$. 


\subsection{The Basic Multi-Period Portfolio Optimization Models}

Assume that the objective of the investor wants to maximize terminal wealth over the whole $T$ periods investment. At the same time, the desired number of assets in the portfolio at each period $t$ must not achieve or exceed the given number. Thus, the multi-period portfolio selection problem can be formulated as the following problem (P1):

$$
\begin{aligned}
\max W_{T+1}=W_{1} & \prod_{t=1}^{T}\left(\sum_{i=1}^{n}\left[\frac{\left(a_{i t}+b_{i t}\right)}{2}+\frac{\left(\beta_{i t}-\alpha_{i t}\right)}{6}\right] x_{i t}+r_{f t}\left(1-\sum_{i=1}^{n} x_{i t}\right)-\sum_{i=1}^{n} c_{i t}\left(\left|x_{i t}-x_{i t-1}\right|\right)\right) \\
\text { s.t. } & \left\{\begin{array}{l}
W_{t+1}=\left(1+\left(\sum_{i=1}^{n}\left[\frac{\left(a_{i t}+b_{i t}\right)}{2}+\frac{\left(\beta_{i t}-\alpha_{i t}\right)}{6}\right] x_{i t}\right.\right. \\
\left.\left.\quad+r_{f t}\left(1-\sum_{i=1}^{n} x_{i t}\right)-\sum_{i=1}^{n} c_{i t}\left(\left|x_{i t}-x_{i t-1}\right|\right)\right)\right) W_{t} \\
\sum_{i=1}^{n}\left(b_{i t}-a_{i t}+\frac{\beta_{i t}+\alpha_{i t}}{3}\right) x_{i t} \leq v_{0} \\
1-\sum_{i=1}^{n} x_{i t} \geq x_{f t}^{b} \\
\sum_{i=1}^{n}-x_{i t} \ln x_{i t} \geq H_{t}, \quad t=1,2, \cdots, T \\
l_{i t} \leq x_{i t} \leq u_{i t}, \quad i=1,2, \cdots, n, t=1,2, \cdots, T
\end{array}\right.
\end{aligned}
$$

The model (P1) consists of an objective, namely, the maximization of the investors' terminal wealth. The details of the model (P1) are shown in Equation (13), where constraint (13)(a) denotes the wealth accumulation constraint; constraint (13)(b) states the absolute deviation of the portfolio $x_{t}$ can't exceed the given minimum risk constraint at each period; constraint (13)(c) indicates the investment proportion of risk-free asset at period $t$ must exceed the given lower bound; constraint (13)(d) represents the desired number of assets in the portfolio must not exceed the given value; constraint (13)(e) states the lower and upper bound constraints of $x_{i t}$.

\section{The Optimization on the Multi-Period Portfolio Selection Model}

The sub-problem of period $t$ of the Model (13) can be transformed into

$$
\begin{aligned}
\max \sum_{i=1}^{n} & {\left[\frac{\left(a_{i t}+b_{i t}\right)}{2}+\frac{\left(\beta_{i t}-\alpha_{i t}\right)}{6}\right] x_{i t}+r_{f t}\left(1-\sum_{i=1}^{n} x_{i t}\right)-\sum_{i=1}^{n} c_{i t}\left(\left|x_{i t}-x_{i t-1}\right|\right) } \\
\text { s.t. } \quad & \left\{\begin{array}{l}
\sum_{i=1}^{n}\left(b_{i t}-a_{i t}+\frac{\beta_{i t}+\alpha_{i t}}{3}\right) x_{i t} \leq v_{0} \\
1-\sum_{i=1}^{n} x_{i t} \geq x_{f t}^{b} \\
\sum_{i=1}^{n}-x_{i t} \ln x_{i t} \geq H_{t} \\
l_{i t} \leq x_{i t} \leq u_{i t}, \quad i=1,2, \cdots, n
\end{array}\right.
\end{aligned}
$$

We propose a forward dynamic programming method to solve Model (13). 
Algorithm The forward dynamic programming method.

Step 1 When $t=1$, because of $W_{1}$ and $x_{0}=\left(x_{10}, \cdots, x_{n 0}\right)$ being given, we use CPLEX to solve the Model (14), then the optimal solution of period $1 x_{1}^{\max ^{*}}=\left(x_{11}^{\max ^{*}}, \cdots, x_{n 1}^{\max ^{*}}\right)$ can be got. At the same time, we can get

$$
\begin{aligned}
W_{2}^{\max ^{*}}=(1 & +\left(\sum_{i=1}^{n}\left[\frac{\left(a_{i 1}+b_{i 1}\right)}{2}+\frac{\left(\beta_{i 1}-\alpha_{i 1}\right)}{6}\right] x_{i 1}\right. \\
& \left.\left.+r_{f 1}\left(1-\sum_{i=1}^{n} x_{i 1}\right)-\sum_{i=1}^{n} c_{i 1}\left(\left|x_{i 1}-x_{i 0}\right|\right)\right)\right) W_{1} .
\end{aligned}
$$

Step 2 When $t=2$, because of $W_{2}$ and $x_{1}=\left(x_{11}, x_{21}, \cdots, x_{n 1}\right)$ being given, we use CPLEX to solve the model (14), then the optimal solution of period $1 x_{2}^{\max ^{*}}=\left(x_{12}^{\max ^{*}}, \cdots, x_{n 2}^{\max ^{*}}\right)$ can be got. At the same time, we can get

$$
\begin{aligned}
W_{3}^{\max ^{*}}=(1 & +\left(\sum_{i=1}^{n}\left(\frac{\left(a_{i 2}+b_{i 2}\right)}{2}+\frac{\left(\beta_{i 2}-\alpha_{i 2}\right)}{6}\right) x_{i 2}^{*}\right. \\
& \left.\left.+r_{f 2}\left(1-\sum_{i=1}^{n} x_{i 2}^{*}\right)-\sum_{i=1}^{n} c_{i 2}\left(\left|x_{i 2}^{*}-x_{i 1}^{*}\right|\right)\right)\right) W_{2}^{\max ^{*}} .
\end{aligned}
$$

Step 3 Using the same method, we can get $W_{t}^{\max ^{*}}, t=4,5, \cdots, T+1$.

\section{Numerical Example}

In this section, a numerical example is given to express the idea of the proposed model. Assume that an investor chooses thirty stocks from Shanghai Stock Exchange for his investment. The stocks codes are respectively S1 (600000), S2 (600005), S3 (600015), S4 (600016), S5 (600019), S6 (600028), S7 (600030), S8 (600036), S9 (600048), S10 (600050), S11 (600104), S12 (600362), S13 (600519), S14 (600900), S15 (601088), S16 (601111), S17 (601166), S18 (601168), S19 (601318), S20 (601328), S21 (601390), S22 (601398), S23 (601600), S24 (601601), S25 (601628), S26 (601857), S27 (601919), S28 (601939), S29 (601988), S30 (601998). He intends to make five periods of investment with initial wealth $W_{1}=1$ and his wealth can be adjusted at the beginning of each period. We assume that the returns, risk and turnover rates of the thirty stocks at each period are represented as trapezoidal fuzzy numbers. We collect historical data of them from April 2006 to December 2010 and set every three months as a period to handle the historical data. Using the simple estimation method in Vercher et al. ${ }^{[53]}$ to handle their historical data, the trapezoidal possibility distributions of the return rates of assets at each period can be obtained as shown in Table 1.1 to Table 1.10.

Suppose that the transaction costs of assets of the two periods investment take the same value $c_{i t}=0.003(i=1,2, \cdots, 30 ; t=1,2, \cdots, 5)$, investment preferences $v_{0}=0.1$, the given minimum entropy in the portfolio at period $t H_{t}=0.6$ or $1.6, t=1,2, \cdots, 5$, the lower bound of the investment proportion of risk-free asset $x_{f t}^{b}=-1$, the borrowing rate of the risk-free asset $r_{b t}=0.017$, the lending rate of the risk-free asset $r_{l t}=0.009, t=1,2, \cdots, 5$, the lower $l_{i t}=0.05$ and upper bound constraints $u_{i t}=0.3(i=1,2, \cdots, 30 ; t=1,2, \cdots, 5)$. 
Table 1.1 The fuzzy return rates on assets of five periods investment

\begin{tabular}{|c|c|c|c|}
\hline Asset $t$ & Asset 1 & Asset 2 & Asset 3 \\
\hline 1 & 0.13000 .15590 .09190 .1026 & $\begin{array}{llll}0.0556 & 0.0943 & 0.0463 & 0.1470\end{array}$ & $\begin{array}{llll}0.0921 & 0.1244 & 0.0670 & 0.0443\end{array}$ \\
\hline 2 & $\begin{array}{lllll}0.1339 & 0.1559 & 0.0771 & 0.1026\end{array}$ & $\begin{array}{llll}0.0603 & 0.1022 & 0.0498 & 0.1390\end{array}$ & 0.09250 .12440 .05210 .0443 \\
\hline 3 & 0.13570 .15590 .06990 .1026 & $\begin{array}{lllll}0.0645 & 0.1069 & 0.0454 & 0.1344\end{array}$ & 0.10340 .12440 .06200 .0443 \\
\hline 4 & $\begin{array}{llll}0.1449 & 0.1582 & 0.0553 & 0.1003\end{array}$ & $\begin{array}{llll}0.0742 & 0.1117 & 0.0391 & 0.1295\end{array}$ & $\begin{array}{llll}0.1059 & 0.1244 & 0.0467 & 0.0443\end{array}$ \\
\hline 5 & $\begin{array}{llll}0.1480 & 0.1583 & 0.0557 & 0.1002\end{array}$ & 0.09430 .11630 .05520 .1249 & 0.10990 .12440 .04970 .0443 \\
\hline
\end{tabular}

Table 1.2 The fuzzy return rates on assets of five periods investment

\begin{tabular}{|c|c|c|c|}
\hline Asset $t$ & Asset 4 & Asset 5 & Asset 6 \\
\hline 1 & 0.10440 .12990 .06040 .0685 & $\begin{array}{lllll}0.0611 & 0.0991 & 0.0601 & 0.0426\end{array}$ & $\begin{array}{llll}0.0899 & 0.1229 & 0.1470 & 0.0451\end{array}$ \\
\hline 2 & 0.11060 .12990 .06460 .0685 & $\begin{array}{llll}0.0702 & 0.0991 & 0.0627 & 0.0426\end{array}$ & $\begin{array}{llll}0.0916 & 0.1229 & 0.1477 & 0.0451\end{array}$ \\
\hline 3 & 0.12100 .12990 .07040 .0685 & $\begin{array}{l}0.08090 .09910 .04120 .0426\end{array}$ & $\begin{array}{llll}0.0936 & 0.1229 & 0.0946 & 0.0451\end{array}$ \\
\hline 4 & $\begin{array}{llll}0.1249 & 0.1299 & 0.0708 & 0.0685\end{array}$ & $\begin{array}{llll}0.0820 & 0.0991 & 0.0421 & 0.0426\end{array}$ & $\begin{array}{lllll}0.0952 & 0.1229 & 0.0624 & 0.0451\end{array}$ \\
\hline 5 & $\begin{array}{llll}0.1250 & 0.1327 & 0.0594 & 0.0657\end{array}$ & $\begin{array}{llll}0.0860 & 0.0991 & 0.0429 & 0.0426\end{array}$ & $\begin{array}{llll}0.1029 & 0.1229 & 0.0627 & 0.0451\end{array}$ \\
\hline
\end{tabular}

Table 1.3 The fuzzy return rates on assets of five periods investment

\begin{tabular}{|c|c|c|c|}
\hline Asset $t$ & Asset 7 & Asset 8 & Asset 9 \\
\hline 1 & $\begin{array}{llll}0.0675 & 0.0920 & 0.0439 & 0.1571\end{array}$ & $\begin{array}{llll}0.0981 & 0.1495 & 0.0558 & 0.0766\end{array}$ & $0.05130 .0765-0.13960 .0825$ \\
\hline 2 & 0.07280 .10850 .04640 .1406 & $\begin{array}{llll}0.1022 & 0.1495 & 0.0523 & 0.0766\end{array}$ & $\begin{array}{llll}0.0714 & 0.0866 & 0.0597 & 0.0790\end{array}$ \\
\hline 3 & $\begin{array}{lllll}0.0863 & 0.1120 & 0.0426 & 0.1371\end{array}$ & $\begin{array}{lllll}0.1058 & 0.1495 & 0.0546 & 0.0766\end{array}$ & $\begin{array}{llll}0.0765 & 0.0870 & 0.0553 & 0.0786\end{array}$ \\
\hline 4 & 0.08870 .11710 .04090 .1320 & 0.12710 .14950 .04260 .0766 & $\begin{array}{llll}0.0813 & 0.0908 & 0.0597 & 0.0748\end{array}$ \\
\hline 5 & $\begin{array}{llll}0.0920 & 0.1217 & 0.0385 & 0.1274\end{array}$ & $\begin{array}{llll}0.1385 & 0.1528 & 0.0540 & 0.0733\end{array}$ & $\begin{array}{llll}0.0846 & 0.0921 & 0.0612 & 0.0735\end{array}$ \\
\hline
\end{tabular}

Table 1.4 The fuzzy return rates on assets of five periods investment

\begin{tabular}{|c|c|c|c|}
\hline Asset $t$ & Asset 10 & Asset 11 & Asset 12 \\
\hline 1 & $\begin{array}{llll}0.0310 & 0.0443 & 0.0258 & 0.0347\end{array}$ & $\begin{array}{llll}0.0510 & 0.0639 & 0.0338 & 0.1217\end{array}$ & $\begin{array}{llll}0.1048 & 0.1438 & 0.0975 & 0.1645\end{array}$ \\
\hline 2 & $\begin{array}{llll}0.0345 & 0.0475 & 0.0227 & 0.0314\end{array}$ & $\begin{array}{llll}0.0534 & 0.0650 & 0.0345 & 0.1206\end{array}$ & 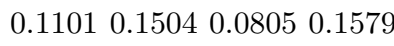 \\
\hline 3 & $\begin{array}{llll}0.0440 & 0.0497 & 0.0289 & 0.0292\end{array}$ & $\begin{array}{llll}0.0556 & 0.0781 & 0.0261 & 0.1075\end{array}$ & $\begin{array}{llll}0.1253 & 0.1506 & 0.0700 & 0.1577\end{array}$ \\
\hline 4 & $\begin{array}{lllll}0.0442 & 0.0518 & 0.0276 & 0.0271\end{array}$ & 0.06360 .08110 .03090 .1045 & 0.14040 .15770 .07560 .1506 \\
\hline 5 & $\begin{array}{llll}0.0443 & 0.0540 & 0.0269 & 0.0249\end{array}$ & $\begin{array}{llll}0.0639 & 0.0842 & 0.0251 & 0.1014\end{array}$ & $\begin{array}{llll}0.1438 & 0.1641 & 0.0650 & 0.1442\end{array}$ \\
\hline
\end{tabular}


Table 1.5 The fuzzy return rates on assets of five periods investment

\begin{tabular}{|c|c|c|c|}
\hline Asset $t$ & Asset 13 & Asset 14 & Asset 15 \\
\hline 1 & $\begin{array}{llll}0.1778 & 0.2319 & 0.0973 & 0.1060\end{array}$ & $\begin{array}{llll}0.0508 & 0.0746 & 0.0489 & 0.0364\end{array}$ & $\begin{array}{llll}0.1422 & 0.1550 & 0.0934 & 0.0826\end{array}$ \\
\hline 2 & 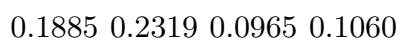 & $\begin{array}{llll}0.0588 & 0.0746 & 0.0525 & 0.0364\end{array}$ & $\begin{array}{llll}0.1485 & 0.1550 & 0.0982 & 0.0826\end{array}$ \\
\hline 3 & $\begin{array}{llll}0.2068 & 0.2319 & 0.1110 & 0.1060\end{array}$ & $\begin{array}{llll}0.0653 & 0.0746 & 0.0516 & 0.0364\end{array}$ & 0.15040 .15710 .09990 .0806 \\
\hline 4 & 0.21310 .23190 .11540 .1060 & $\begin{array}{lllll}0.0685 & 0.0746 & 0.0468 & 0.0364\end{array}$ & $\begin{array}{llll}0.1505 & 0.1624 & 0.0474 & 0.0752\end{array}$ \\
\hline 5 & $\begin{array}{llll}0.2156 & 0.2319 & 0.0947 & 0.1060\end{array}$ & $\begin{array}{llll}0.0716 & 0.0746 & 0.0384 & 0.0364\end{array}$ & $\begin{array}{llll}0.1519 & 0.1680 & 0.0472 & 0.0696\end{array}$ \\
\hline
\end{tabular}

Table 1.6 The fuzzy return rates on assets of five periods investment

\begin{tabular}{|c|c|c|c|}
\hline Asset $t$ & Asset 16 & Asset 17 & Asset 18 \\
\hline 1 & $\begin{array}{llll}0.0403 & 0.0833 & 0.5030 & 0.2098\end{array}$ & $\begin{array}{llll}0.1232 & 0.1621 & 0.0808 & 0.0701\end{array}$ & $\begin{array}{llll}0.0648 & 0.1183 & 0.0612 & 0.4231\end{array}$ \\
\hline 2 & $\begin{array}{llll}0.0417 & 0.0833 & 0.2587 & 0.2098\end{array}$ & $\begin{array}{llll}0.1479 & 0.1621 & 0.0913 & 0.0701\end{array}$ & $\begin{array}{llll}0.0740 & 0.1625 & 0.0694 & 0.3789\end{array}$ \\
\hline 3 & $\begin{array}{lllll}0.0443 & 0.0868 & 0.0301 & 0.2063\end{array}$ & $\begin{array}{llll}0.1485 & 0.1621 & 0.0825 & 0.0701\end{array}$ & $\begin{array}{llll}0.0748 & 0.1949 & 0.0564 & 0.3465\end{array}$ \\
\hline 4 & $\begin{array}{lllll}0.0473 & 0.1020 & 0.0186 & 0.1911\end{array}$ & $\begin{array}{lllll}0.1529 & 0.1621 & 0.0798 & 0.0701\end{array}$ & $\begin{array}{llll}0.0889 & 0.2044 & 0.0647 & 0.3369\end{array}$ \\
\hline 5 & $\begin{array}{llll}0.0606 & 0.1064 & 0.0277 & 0.1867\end{array}$ & $\begin{array}{llll}0.1531 & 0.1626 & 0.0487 & 0.0696\end{array}$ & $\begin{array}{llll}0.1183 & 0.2144 & 0.0641 & 0.3269\end{array}$ \\
\hline
\end{tabular}

Table 1.7 The fuzzy return rates on assets of five periods investment

\begin{tabular}{|c|c|c|c|}
\hline Asset $t$ & Asset 19 & Asset 20 & Asset 21 \\
\hline 1 & $\begin{array}{llll}0.0760 & 0.1000 & 0.0840 & 0.0550\end{array}$ & $\begin{array}{llll}0.1100 & 0.1284 & 0.0578 & 0.0552\end{array}$ & $\begin{array}{llll}0.0519 & 0.0833 & 0.0419 & 0.1091\end{array}$ \\
\hline 2 & $\begin{array}{llll}0.0832 & 0.1000 & 0.0632 & 0.0550\end{array}$ & $\begin{array}{llll}0.1150 & 0.1284 & 0.0566 & 0.0552\end{array}$ & 0.05240 .08840 .03640 .1040 \\
\hline 3 & $\begin{array}{llll}0.0856 & 0.1000 & 0.0636 & 0.0550\end{array}$ & $\begin{array}{llll}0.1152 & 0.1284 & 0.0554 & 0.0552\end{array}$ & $\begin{array}{llll}0.0752 & 0.0923 & 0.0580 & 0.1001\end{array}$ \\
\hline 4 & $\begin{array}{llll}0.0880 & 0.1000 & 0.0440 & 0.0550\end{array}$ & $\begin{array}{llll}0.1200 & 0.1285 & 0.0473 & 0.0550\end{array}$ & $\begin{array}{llll}0.0798 & 0.0961 & 0.0599 & 0.0963\end{array}$ \\
\hline 5 & 0.09030 .10000 .04230 .0550 & $\begin{array}{llll}0.1217 & 0.1320 & 0.0215 & 0.0516\end{array}$ & $\begin{array}{llll}0.0833 & 0.1001 & 0.0619 & 0.0923\end{array}$ \\
\hline
\end{tabular}

Table 1.8 The fuzzy return rates on assets of five periods investment

\begin{tabular}{|c|c|c|c|}
\hline Asset $t$ & Asset 22 & Asset 23 & Asset 24 \\
\hline 1 & 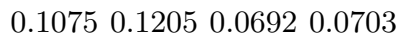 & $\begin{array}{llll}0.0123 & 0.0439 & 0.1039 & 0.2054\end{array}$ & $\begin{array}{llll}0.0805 & 0.1082 & 0.0765 & 0.0257\end{array}$ \\
\hline 2 & $\begin{array}{llll}0.1134 & 0.1205 & 0.0582 & 0.0703\end{array}$ & $\begin{array}{lllll}0.0151 & 0.0756 & 0.0834 & 0.1737\end{array}$ & $\begin{array}{llll}0.0811 & 0.1082 & 0.0501 & 0.0257\end{array}$ \\
\hline 3 & $\begin{array}{llll}0.1162 & 0.1238 & 0.0585 & 0.0670\end{array}$ & $\begin{array}{llll}0.0221 & 0.0840 & 0.0899 & 0.1653\end{array}$ & $\begin{array}{llll}0.0886 & 0.1082 & 0.0530 & 0.0257\end{array}$ \\
\hline 4 & $\begin{array}{llll}0.1197 & 0.1272 & 0.0618 & 0.0636\end{array}$ & $\begin{array}{lllll}0.0231 & 0.0916 & 0.0587 & 0.1577\end{array}$ & $\begin{array}{llll}0.0928 & 0.1082 & 0.0471 & 0.0257\end{array}$ \\
\hline 5 & 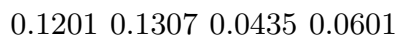 & $\begin{array}{llll}0.0439 & 0.0996 & 0.0437 & 0.1498\end{array}$ & $\begin{array}{llll}0.0959 & 0.1082 & 0.0431 & 0.0257\end{array}$ \\
\hline
\end{tabular}

Table 1.9 The fuzzy return rates on assets of five periods investment

\begin{tabular}{|c|c|c|c|}
\hline Asset $t$ & Asset 25 & Asset 26 & Asset 27 \\
\hline 1 & $\begin{array}{llll}0.0921 & 0.1100 & 0.0692 & 0.0511\end{array}$ & $\begin{array}{llll}0.1054 & 0.1440 & 0.0824 & 0.1098\end{array}$ & $\begin{array}{llll}0.0282 & 0.0455 & 0.2042 & 0.1811\end{array}$ \\
\hline 2 & $\begin{array}{llll}0.0941 & 0.1100 & 0.0572 & 0.0511\end{array}$ & $\begin{array}{llll}0.1111 & 0.1440 & 0.0741 & 0.1098\end{array}$ & $\begin{array}{llll}0.0368 & 0.0508 & 0.1553 & 0.1758\end{array}$ \\
\hline 3 & 0.09740 .11000 .05040 .0511 & $\begin{array}{llll}0.1217 & 0.1440 & 0.0837 & 0.1098\end{array}$ & $\begin{array}{llll}0.0390 & 0.0622 & 0.1410 & 0.1644\end{array}$ \\
\hline 4 & $\begin{array}{llll}0.0976 & 0.1112 & 0.0246 & 0.0499\end{array}$ & 0.13770 .14870 .07570 .1050 & $\begin{array}{llll}0.0412 & 0.0712 & 0.1082 & 0.1554\end{array}$ \\
\hline 5 & 0.10360 .11440 .01890 .0467 & $\begin{array}{llll}0.1400 & 0.1490 & 0.0732 & 0.1048\end{array}$ & $\begin{array}{llll}0.0455 & 0.0783 & 0.0347 & 0.1483\end{array}$ \\
\hline
\end{tabular}


Table 1.10 The fuzzy return rates on assets of five periods investment

\begin{tabular}{|c|c|c|c|}
\hline Asset $t$ & Asset 28 & Asset 29 & Asset 30 \\
\hline 1 & $\begin{array}{llll}0.1291 & 0.1388 & 0.0758 & 0.0962\end{array}$ & $\begin{array}{llll}0.1026 & 0.1201 & 0.0645 & 0.0420\end{array}$ & $\begin{array}{llll}0.0928 & 0.1101 & 0.0600 & 0.0373\end{array}$ \\
\hline 2 & 0.13030 .14600 .07100 .0890 & 0.10450 .12010 .05630 .0420 & $\begin{array}{llll}0.0972 & 0.1101 & 0.0571 & 0.0373\end{array}$ \\
\hline 3 & 0.13240 .14650 .06080 .0885 & $\begin{array}{llll}0.1066 & 0.1201 & 0.0580 & 0.0420\end{array}$ & $\begin{array}{llll}0.0995 & 0.1101 & 0.0592 & 0.0373\end{array}$ \\
\hline 4 & $\begin{array}{llll}0.1345 & 0.1507 & 0.0298 & 0.0843\end{array}$ & $\begin{array}{llll}0.1113 & 0.1201 & 0.0372 & 0.0420\end{array}$ & $\begin{array}{llll}0.1019 & 0.1101 & 0.0533 & 0.0373\end{array}$ \\
\hline 5 & $\begin{array}{llll}0.1388 & 0.1552 & 0.0282 & 0.0798\end{array}$ & $\begin{array}{llll}0.1133 & 0.1217 & 0.0270 & 0.0404\end{array}$ & $\begin{array}{llll}0.1021 & 0.1101 & 0.0310 & 0.0373\end{array}$ \\
\hline
\end{tabular}

For comparison, we also use the discrete approximate iteration method to solve the Model (13). We can obtain the corresponding results as follows. If $H_{t}=0.6$, we can get the optimal solution as the follows:

Table 2 The optimal solution when $H_{t}=0.6$

\begin{tabular}{cccc}
\hline$t$ & \multicolumn{2}{c}{ The optimal investment proportions } \\
\hline 1 & Asset 13 & Asset 18 & otherwise 0 \\
& 0.6 & 0.4 & otherwise 0 \\
2 & Asset 13 & Asset 18 & otherwise 0 \\
& 0.6 & 0.4 & otherwise 0 \\
3 & Asset 13 & Asset 18 & \\
\hline & 0.6 & 0.4 & otherwise 0 \\
\hline 5 & Asset 13 & Asset 18 & \\
\hline & 0.6 & 0.4 & Asset 18 \\
\hline
\end{tabular}

When $H_{t}=0.6$, the optimal investment strategy at period 1 is $x_{131}=0.6, x_{181}=0.4$ and otherwise 0 , which means investor should allocate his initial wealth on asset 13 , asset 18 and otherwise asset by the proportions of $60 \%, 40 \%$ and otherwise 0 among the thirty stocks, respectively. The optimal investment strategy at period 2 is $x_{132}=0.6, x_{182}=0.4$ and otherwise 0 , which means investor should allocate his initial wealth on asset 13 , asset 18 and otherwise asset by the proportions of $60 \%, 40 \%$ and otherwise 0 among the thirty stocks, respectively. The optimal investment strategy at period 3 is $x_{133}=0.6, x_{183}=0.4$ and otherwise 0 , which means investor should allocate his initial wealth on asset 13, asset 18 and otherwise asset by the proportions of $60 \%, 40 \%$ and otherwise 0 among the thirty stocks, respectively. The optimal investment strategy at period 4 is $x_{134}=0.6, x_{184}=0.4$ and otherwise 0 , which means investor should allocate his initial wealth on asset 13, asset 18 and otherwise asset by the proportions of $60 \%, 40 \%$ and otherwise 0 among the thirty stocks, respectively. The optimal investment strategy at period 5 is $x_{135}=0.6, x_{185}=0.4$ and otherwise 0 , which means investor should allocate his initial wealth on asset 13 , asset 18 and otherwise asset by the proportions of $60 \%$, $40 \%$ and otherwise 0 among the thirty stocks, respectively. In this case, the available terminal wealth is 2.514198 . 
If $H_{t}=1.6$, we can get the optimal solution as Table 3 .

Table 3 The optimal solution when $H_{t}=1.6$

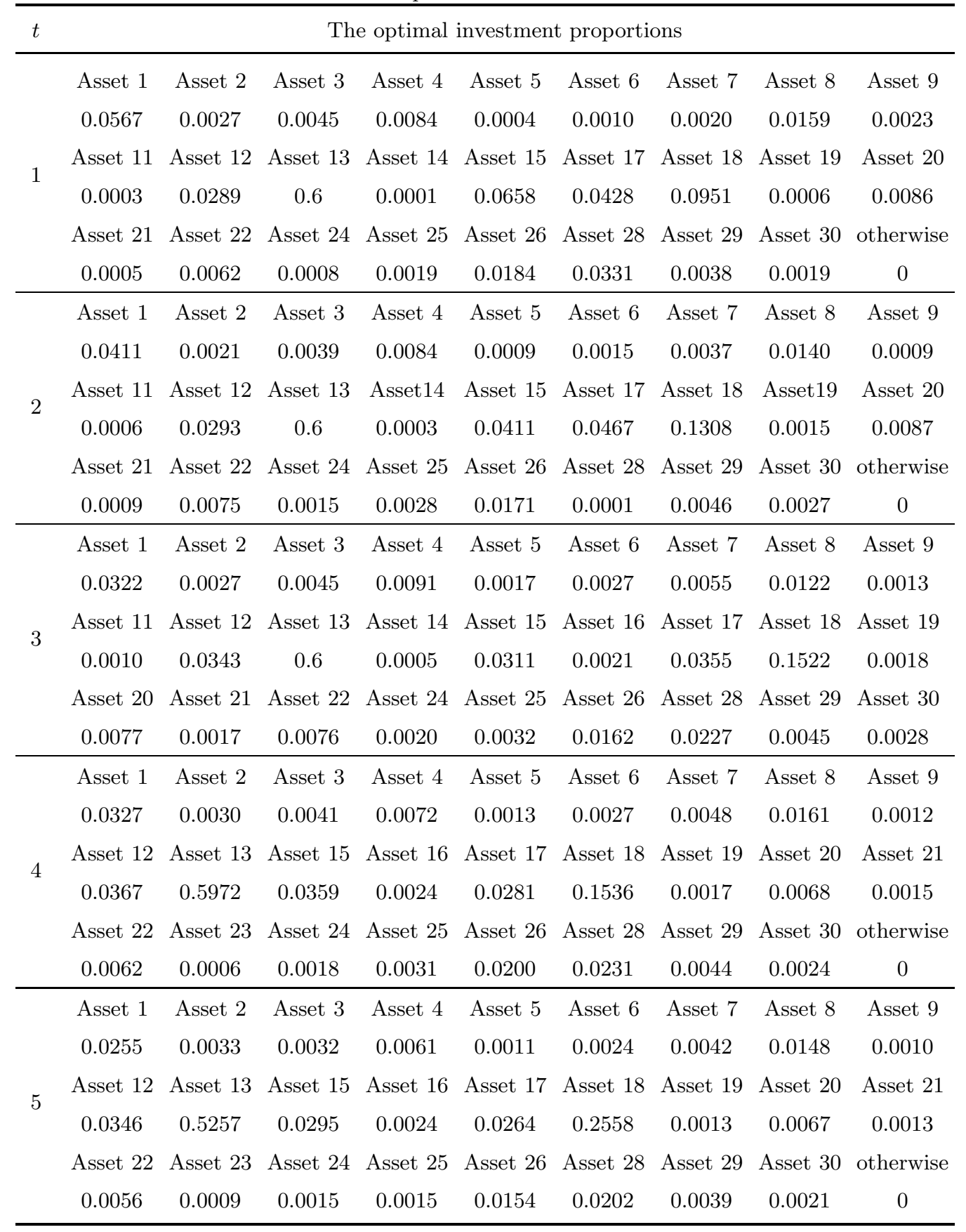

The available terminal wealth is 2.410746 .

To display the influence of $H_{t}$ on the portfolio decision-making, we set its value as 0.6 and 1.6, respectively. Then, we use the Model (13) for portfolio decision-making. After using the discrete approximate iteration method, the corresponding optimal investment strategies can be obtained as shown in Table 2 and Table 3. From Table 2 and Table 3, it can be seen that when 
the preset the desired number of assets in the portfolio become larger, the terminal wealth also becomes larger, which reflects the influence of the desired number of assets on portfolio selection.

From the above calculation, we can get the following solution when the entropy becomes bigger and bigger, the portfolio selection becomes more and more diversified and the terminal wealth becomes smaller and smaller.

\section{Conclusions}

In this paper, we discuss a multi-period portfolio selection problem in fuzzy environment, in which the returns, risk of risky assets are characterized by trapezoidal fuzzy variables rather than single values. We use fuzzy analysis approach to handle the imprecise data in financial markets and propose a multi-period fuzzy portfolio optimization model. Since the proposed model is a fuzzy programming problem, we use the fuzzy decision-making technique to convert it into a crisp form dynamic optimization with path dependence. Through changing the cost function into a variable, the multi-period portfolio selection is approximately turned into the dynamic programming. Furthermore, the discrete approximate iteration method is designed to obtain the optimal portfolio strategy. A numerical example is given to illustrate the application

of the proposed model and demonstrate the effectiveness of the designed algorithm for solving our model.

\section{References}

[1] Markowitz H M. Portfolio selection. Journal of Finance, 1952, 7: 77-91.

[2] Konno H, Yamazaki H. Mean-absolute deviation portfolio optimization model and its applications to Tokyo stock market. Management Science, 1991, 37(5): 519-531.

[3] Simaan Y. Estimation risk in portfolio selection: The mean variance model and the mean-absolute deviation model. Management Science, 1997, 43: 1437-1446.

[4] Speranza M G. Linear programming models for portfolio optimization. The Journal of Finance, 1993, 14: $107-123$.

[5] Feinstein C D, Thapa M N. Notes: A reformation of a mean-absolute deviation portfolio optimization. Manage. Sci., 1993, 39: 1552-1558.

[6] Mossion J. Optimalmultiperiod portfolio policies. Journal of Business, 1968, 41: 215-229.

[7] Hakansson N H. Multi-period mean-variance analysis: Toward a general theory of portfolio choice. Journal of Finance, 1971, 26: 857-884.

[8] Li D, Chan T F, Ng W L. Safety-first dynamic portfolio selection. Dynamics of Continuous, Discrete and Impulsive, Systems Series B: Applications and Algorithms, 1998, 4(4): 585-600.

[9] Li D, Ng W L. Optimal dynamic portfolio selection: Multiperiod mean-variance formulation. Mathematical Finance, 2000, 10(3): 387-406.

[10] Calafiore G C. Multi-period portfolio optimization with linear control policies. Automatica, 2008, 44(10): 2463-2473.

[11] Zhu S S, Li D, Wang S Y. Risk control over bankruptcy in dynamic portfolio selection: A generalized mean-variance formulation. IEEE Transactions on Automatic Control, 2004, 49(3): 447-457.

[12] Wei S Z, Ye Z X. Multi-period optimization portfolio with bankruptcy control in stochastic market. Applied Mathematics and Computation, 2007, 186(1): 414-425.

[13] Güpınar N, Rustem B. Worst-case robust decisions for multi-period mean-variance portfolio optimization. European Journal of Operational Research, 2007, 183(3): 981-1000.

[14] Yu M, Takahashi S, Inoue H, et al. Dynamic portfolio optimization with risk control for absolute deviation model. European Journal of Operational Research, 2010, 201(2): 349-364. 
[15] Cllikyurt U, Öekici S. Multiperiod portfolio optimization models in stochastic markets using the meanvariance approach. European Journal of Operational Research, 2007, 179(1): 186-202.

[16] Yan W, Li S R. A class of multi-period semi-variance portfolio selection with a four-factor futures price model. Journal of Applied Mathematics and Computing, 2009, 29: 19-34.

[17] Yan W, Miao R, Li S R. Multi-period semi-variance portfolio selection: Model and numerical solution. Applied Mathematics and Computation, 2007, 194: 128-134.

[18] Pınar M Ç. Robust scenario optimization based on downside-risk measure for multi-period portfolio selection. OR Spectrum, 2007, 29: 295-309.

[19] Zhang W G, Liu Y J, Xu W J. A possibilistic mean-semivariance-entropy model for multi-period portfolio selection with transaction costs. European Journal of Operational Research, 2012, 222: 41-349.

[20] Zhang W G, Liu Y J, Xu W J. A new fuzzy programming approach for multi-period portfolio Optimization with return demand and risk control. Fuzzy Sets and Systems, 2013, http://dx.doi.org/10. 1016/j.fss.2013.09.002.

[21] Liu Y J, Zhang W G, Xu W J. Fuzzy multi-period portfolio selection optimization models using multiple criteria. Automatica, 2012, 48: 3042-3053.

[22] Liu Y J, Zhang W G, Zhang P. A multi-period portfolio selection optimization model by using interval analysis. Economic Modelling, 2013, 33: 113-119.

[23] Watada J. Fuzzy portfolio selection and its applications to decision making. Tatra Mountains Mathematical Publication, 1997, 13: 219-248.

[24] León T, Liem V, Vercher E. Viability of infeasible portfolio selection problems: A fuzzy approach. European Journal of Operational Research, 2002, 139: 178-189.

[25] Tanaka H, Guo P. Portfolio selection based on upper and lower exponential possibility distributions. European Journal of Operational Research, 1999, 114: 115-126.

[26] Tanaka H, Guo P, Türksen I B. Portfolio selection based on fuzzy probabilities and possibility distributions. Fuzzy Sets and Systems, 2000, 111: 387-397.

[27] Inuiguchi M, Tanino T. Portfolio selection under independent possibilistic information. Fuzzy Sets and Systems, 2000, 115: 83-92.

[28] Wang S Y, Zhu S S. On fuzzy portfolio selection problems. Fuzzy optimization and Decision Marking, 2002, 1: $361-377$.

[29] Lai K K, Wang S Y, et al. A class of linear interval programming problems and its application to portfolio selection. IEEE Transactions on Fuzzy Systems, 2002, 10: 698-704.

[30] Giove S, Funari S, Nardelli C. An interval portfolio selection problems based on regret function. European Journal of Operational Research, 2006, 170: 253-264.

[31] Zhang W G, Nie Z K. On admissible efficient portfolio selection problem. Applied Mathematics and Computation, 2004, 159: 357-371.

[32] Zhang W G, Liu W A, Wang Y L. On admissible efficient portfolio selection: Models and algorithms. Applied Mathematics and Computation, 2006, 176: 208-218.

[33] Dubois D, Prade H. Possibility Theory. Plenum Press, New York, 1988.

[34] Carlsson C, Fullér R. On possibilistic mean value and variance of fuzzy numbers. Fuzzy Sets and Systems, 2001, 122: 315-326.

[35] Huang X. Mean-variance model for fuzzy capital budgeting. Computers \& Industrial Engineering, 2008, 55: $34-47$.

[36] Huang X. Mean-Semivariance models for fuzzy portfolio selection. Journal of Computational and Applied Mathematics, 2008, 217: 1-8.

[37] Huang X. Risk curve and fuzzy portfolio selection. Computers and Mathematics with Applications, 2008, 55: $1102-1112$.

[38] Zhang W G, Wang Y L, Chen Z P, et al. Possibilistic mean-variance models and efficient frontiers for portfolio selection problem. Information Sciences, 2007, 177: 2787-2801.

[39] Zhang W G. Possibilistic mean-standard deviation models to portfolio selection for bounded assets. Applied Mathematics and Computation, 2007, 189: 1614-1623.

[40] Zhang W G, Xiao W L. On weighted lower and upper possibilistic means and variances of fuzzy numbers and its application in decision. Knowledge and Information Systems, 2009, 18: 311-330.

[41] Li X, et al. A hybrid intelligent algorithm for portfolio selection problem with fuzzy returns. Journal of 
Computational and Applied Mathematics, 2009, 233: 264-278.

[42] Li X, Qin Z, Kar S. Mean-variance-skewness model for portfolio selection with fuzzy returns. European Journal of operational Research, 2010, 202: 239-247.

[43] Carlsson C, Fulle'r R, Majlender P. A possibilistic approach to selecting portfolios with highest utility score. Fuzzy Sets and Systems, 2002, 131: 13-21.

[44] Deng X, Li R J. A portfolio selection model with borrowing constraint based on possibility theory. Applied Soft Computing, 2012, 12: 754-758.

[45] Sadjadi S J, Seyedhosseini S M, Hassanlou K. Fuzzy multi period portfolio selection with different rates for borrowing and lending. Applied Soft Computing, 2011, 11: 3821-3826.

[46] Arnott R D, Wagner W H. The measurement and control of trading costs. Financial Analysts Journal, 1990, 6: 73-80.

[47] Yoshimoto A. The mean-variance approach to portfolio optimization subject to transaction costs. Journal of the Operational Research Society of Japan, 1996, 39: 99-117.

[48] Bertsimas D, Pachamanova D. Robust multiperiod portfolio management in the presence of transaction costs. Computers and Operations Research, 2008, 35: 3-17.

[49] Gulpınar N, Rustem B, Settergren R. Multistage stochastic mean-variance portfolio analysis with transaction cost. Innovations, in Financial and Economic Networks, 2003, 3: 46-63.

[50] Fang Y, Lai K K, Wang S Y. Portfolio rebalancing model with transaction costs based on fuzzy decision theory. European Journal of Operational Research, 2006, 175: 879-893.

[51] Kapur J N. Maximum Entropy Models in Science and Engineering. Wiley Eastern Limited, New Delhi, 1990.

[52] Jana P, Roy T K, Mazumder S K. Multi-objective possibilistic model for portfolio selection with transaction cost. Journal of Computational and Applied Mathematics, 2009, 1: 188-196.

[53] Vercher E, Bermudez J, Segura J. Fuzzy portfolio optimization under downside risk measures. Fuzzy Sets and Systems, 2007, 158: 769-782. 